\title{
On Hui-neng's Ontology That Regards Xin as the Origin
}

\author{
Li Bingquan ${ }^{1,2, ~ *, ~ D u ~ H a i x i n ~}{ }^{3}$, Zhang Xudong ${ }^{1}$ \\ ${ }^{1}$ Educational Science School, Zhaoqing University, Zhaoqing, China \\ ${ }^{2}$ Guangdong Xinzhou Sixth Ch'an Patriarch Hui-neng Culture Research Institute, Xinxing, China \\ ${ }^{3}$ Educational Science School, Henan University, Kaifeng, China
}

\section{Email address:}

libq1221@163.com (Li Bingquan),716826955@qq.com (Du Haixin), zhangxudong802@163.com (Zhang Xudong)

${ }^{*}$ Corresponding author

\section{To cite this article:}

Li Bingquan, Du Haixin, Zhang Xudong. On Hui-neng's Ontology That Regards Xin as the Origin. International Journal of Philosophy. Vol. 7, No. 2, 2019, pp. 82-86. doi: 10.11648/j.ijp.20190702.16

Received: April 30, 2019; Accepted: June 19, 2019; Published: June 29, 2019

\begin{abstract}
Hui-neng, the sixth patriarch of Chinese Ch'an (Zen), traced the origin of the world where human beings exist, and made the explanation with unique Chinese cultural characteristics. He put forward the ontological thought of Xin (mind or heart), which can be reduced to the following two aspects. (1) Human Xin creates the world, which means "the world where human being lives and everything in it are created by human mind." It does not mean that people's Xin create the universe, but creates the world in which they live or the universe in their mind. In other word, the world where everyone lives and all things in it are created by his Xin. Because everyone's Xin is unique, the world created by his Xin is particular. In other words, anyone has his own unique world. (2) "Human Xin is empty". Hui-neng took "Xin is Buddha, Buddha is empty" and "all dharmas are empty" as the core and foundation of his thought, and attributed the Xin down to emptiness. Because he attributed the world's origin to the Xin that was originally empty, the world's origin is able to be come down to emptiness at long last. It is the reason that Xin was empty, so that it is so large enough to hold (or accept) everything and produce everything. Because everything is empty, people do not have to pursue them, they are only external objects. Anyone who thinks in this way would not be troubled by external things. As the result, he keep his mind peaceful and ethereal.
\end{abstract}

Keywords: The Sixth Patriarch Hui-neng, Ontology, Xin (Heart or Mind), Self-Nature, Noumenon (Ontos), Ch'an (Zen)

\section{Introduction: Ontos, Ontology and Hui-neng's Ontology of Xin}

The Sixth Patriarch's Dharma Jewel Platform Sutra laid the foundation of Ch'an [1], which author is Hui-neng who is regarded as the true initiator of Chinese Ch'an [1-3]. He put forward the ontological thought of Xin (heart or mind), which put Xin in the position of noumenon (ontos), root and former.

Ontology is a philosophical or theoretical idea about the origin or matrix of the world. In general, ontology is the doctrine about what exactly the world is or is made of, namely what is the origin that makes up of the world and the objective things in it. The everyday concept of noumenon (ontos) refers to the thing itself, namely the nature of things. Its philosophical concept is a concept opposite to phenomenon, which refers to the fundamental entity forming phenomenon, the true nature of objects and the entity that constitutes them or the fundamental entity behind the phenomenon. "Ontology" is a word coming from the Latin "ontos", and its English equivalent is "To Be" or "Being". So it could be said that "noumenon" refers to the provision of the essence or nature or attribute of things.

From the perspective of "To $\mathrm{Be}$ ", "Be" is a link verb to connect the subject and the object in linguistics. Therefore, every question of "what is XX?" such as "what is human being?" "what is the world?" "what is psychology?" "what is beauty?" etc. is an ontological question. Every one of the statements expressed in such linguistic forms, such as "Human being is an animal that can speak, make and use tools", "Mind is a reflection of objective reality", "Mind is the function of the brain" etc. is an ontological statement. In such a statement, the subject is a defined noun and a concept or object whose ontology need to be clarified. The object is the definition or stipulation of the nature, attribute or feature of the subject words. The definition of ontology should be the 
unique, absolute and stable property, attribute or feature of the subject, which is essential attributes or features. Just as Plato's exploration and definition of "beauty itself" and "goodness itself". "Beauty" cannot be defined by anything that are born and destroyed, or sometimes born and sometimes destroyed, or non-absolute and concrete, but by the eternal, no beginning and no ending, neither born nor destroyed, neither increasing nor decreasing. The issue of the relationship between matter and consciousness in philosophy is the problem of ontology, which is the problem of ontology what is the first nature, matter or consciousness (spirit).

From the perspective of "Being", "noumenon" is the unique existence form of things, which is different from other things and representing the unique existence of the essence of things. Ontology must make a unique explanation or interpretation of the existence of things. The issue of the relationship between thought and being in philosophy is such an ontological problem, Which is the origin, thought or being, or whether or not is there identity between thought and existence.

Since "noumenon" refers to "To Be" or "Being", and ontology is the theory about "noumenon", so it can be said that ontology is the theory about "To Be" or "Being", which is about generality namely existence and its nature and laws [4]. The issues discussed by ontology are the basic problems of philosophy and the first questions of the western philosophy and the fundamental problems explored by philosophy. The reason is that to seek the origin of everything and to explore the true essence of life are the essential characteristics of human thinking. Human beings always try to find the unchanged in eternal change and the absolute in the relative, and devote to combine ephemeral existence with eternal spirit. Thinkers, regardless of ancient or modern, Chinese or foreign, are always trying to find out the origins of the world and to attribute the origin of the world to a certain substance, spirit, neutral (neither substance nor spirit, but a composite of both), or abstract thing, rule, etc. In short, ontology is actually human's inquiry or exploration of the unchanging nature of things or the origin of the world. In the west, it is all about the search for the noumenon or origin such as that Hesiodos searched or inquired for the most primitive god (Annotation: The most primitive god is the father or first god who is named "Chaos" by Hesiodos) in his theogonia and that Aristotle sought the existence form of the world without higher genera and any species differences above it by the means of genera plus variances (Annotation: It is the problem of metaphysics established by Aristotle. The metaphysical refers to the naturalproperty or essence beyond any physical form. Metaphysics is a theory of a series of essences especially the original essences beyond physics), etc. All of them belong to ontological issues. Since the date of the birth of western philosophy, ontology has become what philosophers had to answer. Thales's water, Pythagoras's number, Anaximander's "apeiron" or "boundless" that is a substance without fixed boundaries, forms and properties, Heraclitus's fire, Parmenides's “1” or "Being”, Democritus's atom, Leibniz's monad, Kant's thing-in-itself, etc, all of them are the answers to ontology for philosophers. The inquiry of the most original constitution of things in physics is also an ontological problem.

As one of the three sages in the Oriental (Annotation: Chinese thinkers Lao tzu, Confucius and Hui-neng are honored as the three sages of the Orient in the world), Hui-neng put forward the ontological thought with Chinese Buddhism characteristics, which is the ontology of Xin, which takes Xin as the noumenon or the root of the world and places Xin in the original position before the world. His thought shows that Xin is the origin of human being and the world where he lives. Human being and the world are created by Xin. Human existence is the existence of Xin. The way and quality of human existence is determined by Xin. His view is quite similar to that of today western philosophy of mind. The philosophy of mind has established a new ternary structure of "mind-language-world" [5], which puts mind in the ontological and fundamental and preceding position before language and the world [6]. The noumenon means that Xin is in the ontological position and the core of human existence [7]. The fundamentality means that Xin is fundamental to human beings and the world where human being lives. The pre-existence means that Xin exists before human being and the world [6].

In the same way as Hesiodos's inquiry for the most original god and Aristotle's inquiry for the origin of all things in the world, Hui-neng also traced the origin of the world where human beings exist, and made the explanation with unique Chinese cultural characteristics. His thought can be reduced to the following two aspects.

\section{The World Is Produced by Xin}

Hui-neng regards Xin as the origin of the existence of human being and the world, and put forward the idea that Xin produces the world. His thought can be expressed as follows: Human being and the world and the various things in it are all created by Xin. They are born in Xin, which are the notions, ideas and marks created by Xin. For the world where people live and all things in it, there isn't anything without the nature of mind or leaving no trace of the effect of Xin. Of course, we can see by the analysis of Hui-neng's thought, that "the world is created by Xin" said by him is the meaning that "Xin creates the universe in which the subject lives or the universe that exists in the subjective Xin", rather than that Xin creates the objective universe independent of the subject. In other words, although the external objective world and all things in it appear the same to all people, they are understood, felt, experienced, desired in quite different ways by different people because people's Xin are different. Therefore, the world and all things in it in every mind are different due to the function of people's Xin [8]. In this sense, it is able to be said that the world and all things in it in people's mind are made by Xin, and that people's Xin is noumenon and root and preexistence for people's existence and the world where they live [6] In fact, the environment that the whole Buddhism defines is the environment that includes subjective and objective factors. Any notion or concept also contains two 
aspects of the objective and subjective, which is the result of the interaction of both of the objective and subjective [9].

Hui-neng did not give a specific answer to the ontological question of the relation between thought and existence, but his answer could be inferred from his argument. According to his argument, although "Being" is earlier than the effect of Xin, without the effect of Xin, people do not know whether or not the world including themselves and the objective things in it exist, why exist, how exist. In this sense, it is able to be said that the effect of Xin is before the existence, or the existence is the result of the effect of Xin. All existences are the existences under the effect of Xin. How people's Xin works on their own existence would affect their existence in turn. This is mainly reflected in the following aspects: (1) people's Xin determines whether or not things and people exist. (2) The effect or influence of things or matters on people is restricted by the effect of their own Xin. (3) Although many things or matters exist, they do not exist in people's Xin because they are not acted upon by people's Xin. Although many things or matters do not exist, they exist under the action of people's Xin (mainly imagination, illusion, etc.). There are something that are completely created by people's Xin. (4) It can only be determined by people's Xin whether there exist something or whether they are true or false. It is possible for people's Xin to regard something unreal or virtual as real and some real things as illusory. (5) It is possible that people's Xin would be hoodwinked, deceived or misled by all kinds of false phenomena, and that people's Xin would also deceive itself by making something believed to be true [6]. To sum up, there is no origin of the world independent of people's Xin. People live in the world created by their own Xin. Because of this, what kind of world one's Xin creates, what kind of existence he is. One lives in a world as big as his Xin. The quality and condition of one's existence are subject to his own Xin. This tells us the importance of cultivating the mind for the existence of human beings.

The thought of Hui-neng is similar to the constructivism today. Perhaps the constructivism is influenced by the thought of Hui-neng's Ch'an. Constructivism believes that knowledge and human being are a result of construction. Knowledge does not reflect the nature or law of things, but rationalizes human experience, which is the subjective construction of the world and all things and the subject himself. It is the process of constructing and generating meaning actively. The world where people live is constructed by themselves, which is made up of the meanings constructed by people themselves [10]. However, compared with constructivism, the thought of Hui-neng is more thorough and straight to the origin of human heart [11].

The thought of Hui-neng reflects the differences between Chinese and Western thought, especially between Chinese Ch'an founded by Hui-neng and Western Christianity. Western Christianity, whether Roman Catholicism, Protestantism or Orthodox, all have established the Creator-God according to western ontological ideas. All of them ask their believers to pray for God's salvation in order to go into heaven after death. But Hui-neng did not, instead, he told people to turn to themselves. The foundation and core of Hui-neng's Ch'an is "to find one's true self", which is "to let one know the Xin or self-nature of himself", "self-cultivation, self-practice, self-becoming-Buddha". The thought is consistent with the traditional Confucian and Taoist thought of self-cultivation.

He believed that Buddha is enlightened, namely that an enlightened man would become a Buddha. Therefore, if one wants to become a Buddha, he should first be enlightened, otherwise no one can take him across. He clearly told people to give themselves over to their own heart, and seek the Buddha in their own heart, which essence is that people know themselves and improve their mental realm. It is obviously a kind of self-control thought. One's mind and behavior are mastered by his self-mind or his self-nature. The cause of one's mind and behavior must be found in his heart. Hui-neng pointed out: "The deluded person recites the Buddha's name, seeking rebirth there, while the enlightened person purifies his own mind. Therefore the Buddha said, 'As the mind is purified, the Buddhaland is purified.' If the person of the East purifies his mind, he is sinless. Even though one may be of the West, if his mind is impure, he is sinful. The person of the East commits offenses and recites the Buddha's name, seeking rebirth in the West. When the person of the West commits offenses and recites the Buddha's name, where does he seek rebirth? Fool people do not understand their self-nature and do not know that the Pure Land is within themselves'. Therefore they make vows for the East and West. To enlightened people, all places are the same. As Buddha said, 'in whatever place one dwells, there is constant peace and happiness.' " $[1,12,13]$

\section{Xin (Heart) Is Empty}

Hui-neng took "Xin (heart) is Buddha, Buddha is empty" and "all laws are empty" as the core and foundation of his thought, and attributed the Xin down to emptiness [14]. In his opinion, the self-nature is an absolute entity, with nothing in itself, neither good nor evil [15]. Because he attributed the world's origin to the Xin that was originally empty, the world's origin is able to be come down to emptiness at long last. Hui-neng ever said the verse: "Bodhi is not tree, nor is the bright mirror. Originally there is not a single thing, where can dust alight?" (Annotation: This is the first verse written by Huineng after his enlightenment. As a result of theverse he was recognized by the fifth Patriarch-Hung-jen, and transmitted the robe and bowl of Zen, so became the sixth patriarch in Zen's history. Therefore, the verse is called the verse of the robe and bowl or enlightenment or becoming patriarch) Its main meaning is: Xin and Buddha are originally empty, therefore whatever is seen by Xin in the world is all empty. Now that Xin is originally empty, there is just as well no need to resist all kinds of temptations from the outside world. Anything and any notions would not leave any trace in the empty Xin when they go through the Xin. Because Xin is empty, the pursuit of various external things, such as fame and wealth, etc., which is created by Xin, is also empty. Since everything is empty [16], people do not have to pursue them, 
they are only external objects, which life does not bring and death does not take away [17]. If one thinks in this way, he would not be troubled by external things. As the result, he keep his mind peaceful and ethereal, thus he can produce the morality of the mind-ground without wrong and the concentration of the mind-ground without confusion and the wisdom of the mind-ground without delusion [18].

Hui-neng believed that it just was the reason that Xin was empty so that it was large enough to hold (or accept) everything and produce everything. He pointed out: "What is meant by Maha? Maha means 'great.' The capacity of the mind is vast and great like empty space, and has no boundaries. It is not square or round, great or small. Neither is it blue, yellow, red or white. It is not above or below, or long or short. It is with no anger, joy, right, wrong, good, nor evil, and it has no head or tail. All Buddha-lands are ultimately the same as empty space. The wonderful nature of worldly people is originally empty, and there is not a single dharma which can be obtained. The true emptiness of the self-nature is also like this. ...... The emptiness of the universe is able to contain the forms and shapes of the ten thousand things...... The emptiness of the nature of worldly men is also like this. ......the ability of one's own nature to contain the ten thousand dharmas is what is meant by 'great.' The myriad dharmas are within the nature of all people. ...... the mind will be like empty space. Therefore it is said to be 'great,' 'Maha.'" [13] In this passage, Hui-neng clearly pointed out that the Xin (mind) is empty. Because of Xin's emptiness, the capacity of the Xin is so vast and great that there is no boundaries, which is the same as "five aggregates are all empty" in The Heart of Prajna Paramita Sutra- - the Bodhisattva Heart Sutra. According to Hui-neng's view, a person's mind is as big as the world or universe where he lives. The size of his mind depends on his awareness and understanding of the emptiness of his mind. What kind of his thinking decides what kind of the world where he lives is. The world where he lives is created by his mind. Xin (the mind) is Kong (empty), then Kong (the emptiness) gives birth to Y'ou (the having); Y'ou (the having) produces all things in the world. The thought of Hui-neng comes down in one continuous line with the nihilistic thought of Lao-zi and Zhuang-zi and the Taoist. They differ only in that Hui-neng used the Buddhist "empty", and Lao-zi and Zhuang-zi and the Taoist used "Wu (nothingness)". According to the views of Lao-zi and Zhuang-zi and the Taoist, "Wu (nothingness) produced Y'ou (the Having), Y'ou (the Having) creates everything", "Wuji (the infinite or the endless) produced Tai-ji (the Great Extreme); Tai-ji (the Great Extreme) produced Liang-yi (the Two Elementary Forms); Liang-yi (the Two Elementary Forms) produced Si-xiang (the Four Emblematic Symbols), which again produced Ba-gua (the Eight Trigrams). Ba-gua (the Eight Trigrams) produced Everything."

Hui-neng's ontology is further than western ontological thoughts. Western ontological thoughts, no matter materialistic and idealistic, seek the origin of the world. Parmenides, who laid the foundation of western ontology, defined the origin of the world in order to avoid that anyone regard the origin as what they think because of their ignorance of the origin. (1) The origin is not born and never dies. If it can be born, there must be something that gave birth to it, therefore there would be something that is more original than it. If it can be destroyed, it will become nothing. It would be impossible to imagine how nothingness constitutes an entity. People would have no way of knowing or grasping it. (2) The origin is only one and not two. If there are two, there must be a more fundamental source of the two. Therefore, "two" is derived, and only "one" is the origin. (3) The origin is perfect. If there is any deficiencies, it is the essence of the individual things, not the essence of all. It is according to Parmenides's standards that western philosophy has been searching for a unique origin that makes up the world. God in Christianity, Leibnitz's monad and so on, all possess these specifications.

The western traditional ontology has three basic characteristics: "Firstly, it sets up an 'essence' which is separated from the world in advance, or a way of existence which is separated from the phenomenal world, as the 'origin' or 'true existence' of the world. Secondly, it sets the possibility for people to recognize this 'original' or 'true existence', and takes this as the premise, then explores how people achieve this possible cognition, which actually sets the goal of cognition as the repetition and representation of that set 'the origin' or 'the true existence' in people's thinking (language). Thirdly, generally speaking, this path of inquiry and cognition can only be logical. That is to say, logical thinking is the only philosophical thinking" $[16,19]$.

In contrast with it, Hui-neng attributed the origin of the world to "emptiness" according to the thought of the unity of opposites of "emptiness" or "nothingness" and "existence". Although he believed, as Parmenides did, that Xin (mind) as the origin was neither increasing nor decreasing, and neither growing nor dying, the origin that he said was "empty" or "nothingness". When there was nothing in the first place, how can it be increasing or decreasing and growing or dying? In Hui-neng's view, everything is empty, there is no eternal "reality" or "the origin" or "the true existence", only "emptiness" is the real existence, "impermanence" is the real "permanence".

French thinker Descartes thought that any inquiry and reasoning must have a premise, and the final premise is beyond doubt. He eventually found that the premise was the existing "I", so he put forward "I think, therefore I am (ego cogito, ergo sum)", which meant that the "I" that is thinking is there, which is no doubt [6]. He said: "just as I tried to believe that this is all false at the same time, I found that there are some things (for my doubt) is essential, which is the ' $\mathrm{I}$ ' who is thinking. The fact 'I think, therefore I am (ego cogito, ergo sum)' is beyond the doubts of all doubters, therefore, I am beyond all sceptics doubt. I would take it as the first principle of philosophy I pursue." All of the western philosophies after Descartes are affected by him and took this argument from Descartes as an important premise. In contrast with it, Hui-neng denied the premise more thoroughly. He thought "I" am also empty and can also be negated, so the Ch'an created by him ask people not to grasp "I". Hui-neng thought that Wu-yun (the five aggregates) that construct 'I' are impermanence and empty. All things in the 
world, including physical and mental are not eternal, which are born and destroyed and changed in an instant. This is impermanence. All things are undergoing the process of birth and death, so they are painful. Because of impermanence and pain, there is no such a thing as "self", "soul", "entity" or "noumenon", which is "no-self (anatman)". If we understand this concept, we would contemplate and illuminate everything in the world with wisdom, care nothing about gains or losses, become more positive, so that we can get rid of all the troubles and relieve all sufferings.

In the view of Buddhism, people are composed of five aggregates: Se (Form), Shou (Feeling), Xiang (Cognition), Xing (Formation or Impulse or Action) and Shi (Consciousness). Form is all kinds of material things in the world seen by people, including one's own body, which is the material part of me, similar to the physical self in the object ego described by William James. Feeling, Cognition, Formation and Consciousness are the immaterial part of me, the spiritual part, belonging to the social self and the spiritual self in the object self called by James. According to Hui-neng, the "five aggregates" that form "me" are created by the mind (born in the mind). While the mind is empty, so the "five aggregates" are empty too, then "I" that is made up of the "five aggregates" is also empty. Therefore, it is able to be said that there isn't "self" in Hui-neng's Ch'an, which is an important prerequisite for people to do well. Once there is "self", people will always think about what to do for "me", which will lead to greed, selfishness, fame, anger and infatuation, and then they will be troubled and polluted by these "hearts".

\section{Conclusion}

i. Hui-neng's ontology of Xin can be regarded as the meta-theory that instruct psychological research

ii. It is one basic thought of Hui-neng's ontology that the world where people live is created by people's Xin

iii.It is one basic thought of Hui-neng's ontology that "Xin is Buddha, and Buddha is empty"

iv. Hui-neng puts the Xin in the position of ontos, root and former

v. Hui-neng's thought of ontology is much helpful us to rethink and make clear and understand the basic theoretical problems of psychology

\section{Acknowledgements}

This work was supported by the humanities and social sciences program of Chinese Ministry of Education (Grant number: 15YJAZH029). The topic of program is "The study of the sixth Patriarch of the Zen lineage under the horizon of cultural psychology".

\section{References}

[1] Jia, T.-t. (2011). Jia tao's lecture on the Altar Sutra. Shanghai: Shanghai ancient books press.
[2] Jiang, S.-j. (2014). Platform Sutra and the spread of Chinese zen culture abroad. Journal of Yanshan University (Philosophy and Social Science Edition), 15 (4), 48-53.

[3] Yu, L.-p. (2017). The Reason for Nanchan's Success in the Event of "Emperor Wuzong's Suppressing Buddhism". Journall of Harbin University, 38 (9), 11-15.

[4] Li, B.-q, Zhang, X.-D. (2015). On the Influence of the Mind Turn of Western Philosophy on Psychology. Studies of Psychology and Behavior, 13 (1), 138-143.

[5] Li, B.-q. (2007). Cultural Pschology. Shanghai: Shanghai Education Press.

[6] Li, B.-q, Zhang, Xu-D., Ye, Zh.-q. (2018). On the noumenon, fundamentality and preceding of the mind (Xin). Journal of Soochow University (Educational Science Edition), 6 (2), 95-102.

[7] Dant, T. (2015). In two minds: Theory of Mind, intersubjectivity, and autism. Theory \& Psychology, 25 (1), 45-62.

[8] Li B.-q., Zhang X.-d., Ye Zh.-q., Du Sh.-j. (2019). On Huineng's Xinxue of Ch'an and Its Realistic Value. Humanities and Social Sciences, 7 (1), 14-20.

[9] Prueitt, C. (2017). Shifting Concepts: The Realignment of Dharmakirti on Concepts and the Error of Subject/Object Duality in Pratyabhijñā Śaiva Thought. Journal of Indian Philosophy, 45, 21-47.

[10] Li, B.-q. (2007). Comparing current cognitive psychology new approaches with each other Journal of Nanjing Normal University (Social Science) (5), 80-85.

[11] Li B.-q, Zeng W.-x. (2019). The Comparison between Huineng's and Yangming's Heart-Mind Theory. Asia-Pacific Journal of Psychology. 1 (1), 5-11.

[12] Huang, B.-q. (1996). Annotating and Explaining 《Altar Sutra》 of the Sixth Ancestors of Zen. Guangdong: Guangdong Higher Education Press.

[13] Hui-neng. (2001). The Sixth Patriarch's Dharma Jewel Platform Sutra. San Francisco: Sino-American Buddhist Association.

[14] Dai, F.-H. (2019). Theme and Characteristics of Huanglong Chan Sect. Fa Yin. (03), 19-22.

[15] Li Man. (2019). Interpretation of Zen Thoughts in a Hui Neng's Poem. Journal of Yichun University. 2019, 41 (04), 6-11.

[16] Li, B.-q, Ye, Zh.-q., Zhang, Xu-D. (2018). On the Ideas of Xinxue (the philosophy of the mind) Embedded in the Jieyu (Buddhist verse) of the Sixth Ancestor of Zen-Hui Neng. Psychological Exploration, 38 (4), 240-244.

[17] Li Man. (2019). The Natural Truth in the Thought of HuiNeng Zen. Journal of Nanchang Normal University. 2018, 39 (02), 28-32+54

[18] Li, B.-q. (2005). On Mainstream Psychology's Fix \& Cultural Psychology's Springing Up. Journal of Northwest Normal University (Social Sciences), 42 (1), 42-48.

[19] Li, P.-ch. (1994). Meditation on contemporary cultural philosophy. Beijing: Renmin Press. 